\title{
(In)satisfação com o trabalho em saúde mental: um estudo em Centros de Atenção Psicossocial
}

\author{
(Dis) satiffaction with mental healthcare work: \\ a study in Psychosocial Care Centers
}

JoséM aria Ximenes Guimarães ${ }^{1}$

$M$ aria Salete Bessa J orge ${ }^{2}$

M arluce M aria Araújo Assis ${ }^{3}$

\footnotetext{
${ }^{1}$ Laboratório de

Humanização daAtenção e Gestão em Saúde,

Universidade Estadual do Ceará. Av. Paranjana 1.700,

Itaperi. 60740-000

Fortaleza CE.

jm_ximenes@uece.br

${ }^{2}$ Programa de Pós-

Graduação em Saúde

Coletiva, Universidade

Estadual do Ceará.

${ }^{3} \mathrm{~N}$ úcleo de Pesquisa

Integrada em Saúde

Coletiva, Universidade

Estadual deFeira de

Santana.
}

Abstract The scope of this article is to analyze satisfaction in the workplace of mental healthcare professionals who serve in Psychosocial Care Centers (Caps). The research is of a qualitative natureand the data-collecting medium was semistructured interviews with 19 workers of three Capsin Fortaleza, in the N orthern Brazilian State of Ceará. The treatment of the empirical material was based upon the analysis of content with an emphasis on the thematic bias. The results revealed the determinants of (dis) satisfaction present in the daily routine of these workers. The relationships established with the users were singled out as the main source of satisfaction, whereas the work and wage conditions were the main motives for dissatisfaction. In addition to these aspects, consequences of (dis) satisfaction at work in the private, social and organizational field of the workers' life in the Caps were revealed, mainly in physical and mental health. Lastly, they emphasized the urgent need for implementation - on the part of public administration - of strategies that seek to reduce the precariousness of healthcarework, especially in mental health, with a view to mitigating damages potentially caused by such work.

Key words Satisfaction in the workplace, M ental health services, Personnel health management, Qualitative research
Resumo 0 presente artigo tem por objetivo analisar a satisfação de trabalhadores de saúde mental que atuam em Centros deA tenção Psicossocial (Caps). A pesquisa é de natureza qualitativa. 0 instrumento de coleta de dados foi a entrevista semiestruturada, aplicada a 19 trabalhadores de três Caps em Fortaleza (Ceará). 0 tratamento do material empírico baseou-se na análise de conteúdo com ênfase em eixos temáticos. 0 s resultados revelaram os determinantes de (in) sati sfação presentes no cotidiano desses trabalhadores. As relações estabelecidas com os usuários foram referidas como principal causa de satisfação, enquanto as condições de trabal ho e o salário se constituem nos principais motivos de insatisfação. Além desses aspectos, emergiram consequências da (in)satisfação no trabalho no campo particular, social e organizacional da vida dos trabalhadores dos Caps, particularmente na saúde física e mental. Por fim, apontam para a urgência de implementação de estratégias, por parte da administração pública, que visem à desprecarização do trabalho em saúde e, mais particularmente, em saúdemental, tendo em vista a redução dos danos eventualmente causados pel o trabalho.

Palavras-chave Satisfação no trabalho, Serviços desaúdemental, Gestão depessoal em saúde, Pesquisa qualitativa 
Introdução

As transformações ocorridas no modo de produção capitalista têm produzido impacto sobre a força de trabalho. Nesse contexto, novos processos de trabalho estão em curso, nos quais podem ocorrer a flexibilização do seu modo de organização e novas formas de adequação da produção de serviços à lógica do trabal ho. Portanto, o processo de globalização da economia e as tendências de mercado têm provocado alterações no mundo do trabalho. Dessa forma, o trabalho em saúde modifica-se, também, em consonância com os processos produtivos e engendrados pelas mudanças no mundo globalizado ${ }^{1}$.

No setor saúde, particularmente no campo da saúde mental, acrescentam-se aos processos transformadores de caráter macropolítico e econômico os movimentos de reforma do setor, especificamenteo da reforma psiquiátrica, vivenciado nas últimas décadas. Entre os desdobramentos dessa reforma, merece destaque a criação de serviços substitutivos ao modelo manicomial, os quais resultam de um processo histórico de luta pela democratização da saúde no Brasil e busca de superação do modelo de atenção ao doente mental, pautado na exclusão social e cronificação da doença².

0 processo de criação de serviços substitutivos ao hospital psiquiátrico, entre eles os Centros de Atenção Psicossocial (Caps), possibilitou a inserção de novos atores na reorganização da assistência à saúde mental e, consequentemente, mudança na lógica de organização do trabalho nos espaços de atuação dos profissionais, que agora já não têm somente o hospital/asilo como campo de prática. Desse modo, diante das novas possibilidades de organização dos processos de trabalho, emergem novas formas de relação entre os trabalhadores, inclusive a necessidade de se trabal har numa perspectiva interdisciplinar.

Ao observar o contexto apresentado, percebe-se que o trabal ho em saúde mental representa grandes desafios, em virtude de sua complexidade, que comportam diversas interfaces, as quais vão da reestruturação dos serviços à qualidade da assistência prestada, passando pelas relações de trabal ho e pela adoção de novos saberes, tecnologias e metodologias de trabal ho.

Portanto, o processo de mudanças em curso no sistema de saúde brasileiro, desde o início do movimento de reforma do setor na década de 1980, que culminou com a aprovação do Sistema Ú nico de Saúde (SUS) em 1988, tem possibilitado a inserção da saúde mental na agenda muni- cipal como parte das políticas públicas, cujos interesses são direcionados para a reestruturação dos sistemas e serviços de saúde. No entanto, se faz necessário analisar que a implantação de novos serviços, tendo em vista a ampliação de cobertura e/ou substituição de modelos e práticas vigentes, não tem dado respostas resolutivas às demandas da população. Para tanto, considerar possibilidades de ampliação da resolubilidade significa assumir o desafio e, ao mesmo tempo, apostar na instauração de uma série de alterações nos mecanismos de gestão e dos processos de trabalho em saúde, capazes de atender ao mesmo tempo às necessidades de saúde da população e às de satisfação profissional e pessoal dos trabalhadores ${ }^{3}$.

Não obstante, referente à gestão do trabal ho em saúdeno Brasil, reconhece-sequeesta seconstitui em um sério problema para a consolidação do SUS, pois em meio ao seu processo de implantação ocorreu a precarização do trabal ho em saúde4. Deve- se considerar que a assistência produzida e as condições de trabalho são realidades nas quai s objetivos técnicos estão articulados aos objetivos institucionais, sob os quais a técnica se organiza de tal ou qual forma de produzir cuidados. Tal organização representa interesses e políticas administrativas, compromissos, certas disponibilidades demeios de trabal ho, instalaçõese formas de interagir com a clientela; representa, ainda, maior ou menor satisfação no trabalho. Tudo isso é que conformará os padrões do desempenho profissional para o conjunto dos trabalhadores de saúde 5 .

Conforme esse entendimento, e situando os Caps como serviços de saúde mental relativamente recentes, a presente investigação recorta como objeto de análise a satisfação dos trabaIhadores, aqui entendida como capaz de refletir as formas de gestão e organização do trabalho, e as múltiplas relações estabelecidas com os diversos atores no interior desses serviços. Por conseguinte, tem o potencial de fornecer informações que pautem a intervenção dos gestores na (re) organização dos sistemas e serviços de saúde no âmbito do SUS.

No âmbito da saúde mental, tem sido observado um crescente interesse em estudar a satisfação no trabalho. Assim, foram encontrados alguns estudos de avaliação da qualidade $e^{4,6-8}$ de serviços de saúde mental de outras cidades brasileiras, que tomam como objeto de análise a satisfação dos trabalhadores, nos quais foi privilegiada a pesquisa quantitativa. Desse modo, a satisfação no trabalho tem sido avaliada somente em seus 
aspectos objetivos, à medida que é reduzida a operacionalização de variáveis mensuráveis.

No entanto, ao se considerar o trabalho em saúde como prática social e institucional, e a satisfação como resultante da percepção do trabaIhador acerca dessa realidade, observa-se que a satisfação está permeada por aspectos subjetivos e intersubjetivos, os quais a pesqui sa quantitativa não tem a pretensão de analisar. Nessa perspectiva, compreende-se que a realização de estudos qualitativos na área preenche lacunas, pois eles se mostram aptos a apreender os fenômenos sociais e suas relações, respeitando sua complexidade, riqueza e profundidade. Portanto, valoriza a experiência vivencial dos atores sociais envolvidos, na medida em que considera a subjetividade ea intersubjetividade presentes no contexto da pesquisa?.

Considera-se a satisfação no trabalho uma produção subjetiva, elaborada a partir da avaliação do trabalhador em relação ao ambiente de trabalho, sendo atravessada por elementos intrínsecos e extrínsecos ao cotidiano do trabaIho ${ }^{10}$. É determinada pelos aspectos psicossociais do trabal ho - aqueles referentes à interação entre trabalhador e meio ambiente do trabalho, conteúdo do trabalho, habilidades do trabalhador, condições organizacionais, necessidades e cultura. Além disso, as causas pessoais extratrabalho podem, por meio de percepções e experiências, influenciar a saúde, o desempenho ea satisfação do trabalhador ${ }^{11}$.

Com base nessas prerrogativas, o presente estudo tem como objetivo analisar a satisfação e/ou insatisfação com o trabalho entre os membros das equipes de saúde mental que atuam em Centros de Atenção Psicossocial do município de Fortaleza (CE).

\section{Metodologia}

Trata-se de uma pesquisa qualitativa que procura responder a questões muito particulares, tendo em vista que ela se ocupa com um nível da realidade não reduzível a números, por se tratar de um universo composto por significados, motivos, aspirações, crenças, valores eatitudes. Tudo isto corresponde a um espaço mais profundo das relações, dos processos e dos fenômenos que não podem ser reduzidos à operacionalização de variáveis $s^{12}$.

0 estudo foi realizado em três Caps localizados em Fortaleza (CE). N o processo de seleção das instituições integrantes da pesquisa, o crité rio adotado foi o tempo de funcionamento na rede SUS. Foram selecionados os três primeiros Caps implantados, visto que os demais tinham, no início da pesquisa, menos de um ano de funcionamento.

Participaram do estudo 19 trabalhadores de saúde mental, sendo 12 de nível superior (NS) e sete de nível médio (NM). Cabe destacar que todos os participantes são do sexo feminino. A seleção por sexo não foi intencional; deve-se a dois aspectos: a grandemaioria do contingente detrabalhadores dos Caps é composta por mulheres; e os homens convidados a participar da pesquisa declinaram do convite.

A delimitação do total departicipantes se deu por saturação teórico-empírica, considerando a relevância e a repetição dos conteúdos representados nas falas para a compreensão do objeto em apreensão ${ }^{13}$.

A coleta de dados se deu no período de abril a agosto de 2007. Para tal, utilizou-se a entrevista semiestruturada, na qual se abordavam os seguintes pontos: a satisfação no ambiente de trabal ho, as condições de trabal ho e os determinantes psicossociais da (in)satisfação no trabal ho.

Na análisedo material empírico, optou-sepor uma aproximação com a análise de conteúdo, conforme M inayo ${ }^{12}$, com ênfase em eixos temáticos, por possibilitar a descrição e a explicação de um pensamento, o qual pode ser compreendido por meio da linguagem, como núcleoseinstrumentos de comunicação entre os homens. Desse modo, a partir das falas dos entrevistados, procurou-se apreender a realidade por meio do conteúdo manifesto e latente, em busca da objetivação do conhecimento.

Destaca-sequeo projeto de pesquisa foi aprovado pelo Comitê de Ética e Pesquisa da Universidade Estadual do Ceará. Todos os participantes, após esclarecimentos acerca dos objetivos da pesquisa e da preservação de suas identidades, assinaram o Termo de Consentimento Livre e Esclarecido.

\section{Resultados ediscussão}

No caso dos serviços de saúde, o ambiente de trabal ho se configura como cenário em que atuam diversos atores, entre eles gestores, trabal hadores e usuários. Conforma-se, portanto, como uma arena na qual ocorrem inúmeras inter-relações. Por conseguinte, é atravessado por diversos interesses, conflitos, necessidades e satisfações/insatisfações. 
N esse contexto, as tensões e os confrontos existentes, em que estão presentes, de um lado, os interesses institucionais, determinados histórica, política esocialmente, e de outro os interesses dos trabalhadores, quenem sempresão equacionados de forma a atender aos anseios de ambas as partes, podem gerar (in)satisfações para um ou outro polo da relação.

A satisfação no trabalho é determinada por elementos presentes no próprio ambienteem que se realizam as atividades laborais, os quais pertencem a dois grandes grupos: eventos e condições (pagamento, trabalho em si, promoção e reconhecimento, condições e ambiente de trabaIho); e agentes (colegas e subordinados, supervisão e coordenação/gerenciamento, instituição/ organização) ${ }^{10}$.

Ressalta-se que a análise dos elementos presentes nos discursos dos entrevistados evidenciam os determinantes e consequências da (in) satisfação no trabalho, considerando os aspectos psicossociais do trabalho, conforme sistematizado nos eixos temáticos a seguir.

\section{Determinantes psicossociais} da (in)satisfação no trabalho

Ao compreender que os aspectos psicossociais do trabalho são capazes de determinar a (in)satisfação do trabalhador, procurou-se desvelar aqueles presentes no cotidiano dos trabaIhadores de saúde mental.

Condições de trabalho: estrutura física e material/equipamento disponível

Ao fazer referência ao seu ambiente de trabaIho, 17 trabalhadores revelam que nos Caps as condições de trabalho são insatisfatórias, conforme representam as seguintes falas:

[...] com a estrutura física aí, tem muitas insati sfações. (Ent. 2, NS)

Eu não me sinto satisfeita aqui. Eu acho que é muito precário. Instalações, conforto, pra eles não tem. (Ent. 18, N M)

Para as entrevistadas, as instalações físicas dos Caps constituem causa de insatisfação. A preocupação com a estrutura física não tem origem somente na necessidade de conforto pessoal para a execução das atividades cotidianas, mas principalmente no desejo de mel hor atender osusuários, de poder executar a contento as atividades programadas.

Além dos problemas referentes à estrutura física, as entrevistadas apontam para limitações quanto à disponibilidade de material no serviço, dificultando sua operacionalidade, segundo emerge no seguinte discurso:

A nossa dificuldade maior é de retorno dos materiais, de compra dos materiais. (Ent. 4, NS)

As deficiências das instalações ea carência de materiais, além de provocar insatisfações, podem promover limitações na organização e na execução das práticas de saúde mental. No entanto, outras trabalhadoras apresentam opinião divergente quanto à estrutura e aos serviços estudados, reconhecendo que

[...] estamoscom uma estrutura física boa, bem adaptada. (Ent. 10, NS)

[...] a minha satisfação no ambiente de trabaIho é imensa. Com relação às instalações físicas, equipamento e materiais, têm sido contemplados com essa nova gestão. (Ent. 12, NS)

Pode-se supor que a divergência das participantes reside no fato de que o Caps onde atuam foi reformado. É perceptível a satisfação da entrevistada 12 quanto às instalações e disponibilidade de equipamentos e materiais. Do seu discurso emerge a existência de um compromisso, por parte da gestão municipal, no sentido de reestruturar e manter o serviço funcionando, satisfatoriamente. Ainda afirma:

Nós tivemos um ganho com a reforma dasinstalações físicas, está havendo investimento por parte da gestão municipal. (Ent. 12, NS)

Desse modo, pode-se considerar que a implantação/implementação de serviços de saúde, bem como sua manutenção, tendo em vista o fortalecimento do SUS, é determinada pelo contexto político, social eeconômico, particularmente no tocante ao financiamento no campo da saúde mental ${ }^{14}$.

Valorização do trabalho

A valorização no trabalho constitui um dos seus elementos intrínsecos, reconhecida como capaz de inferir na satisfação pessoal e profissional do trabalhador. Nesse contexto, duas entrevistadas asseguram, conforme retrata o discurso, que:

[...] o meu trabalho éval orizado ea gentetenta exercer a atividade. (Ent. 17, N M)

Pode-se inferir que a valorização está relacionada ao reconhecimento do trabalho por parte dos usuários e pessoas que compartilham do mesmo trabalho. Outra entrevistada corrobora esse posicionamento, pois emerge do seu discurso a ideia de que o reconhecimento e o respeito são determinantes da satisfação. Demonstra satisfação em relação ao reconhecimento do seu trabalho pelos usuários, mas apresenta-se insa- 
tisfeita em relação aos gestores, em decorrência da ausência de respeito e reconhecimento.

0 respeito queas pessoas, a chefia/gerência tem por você. Eu me sinto reconhecida pelos usuários. Mas quando o povo da Secretaria vem falar um monte de coisas, eu me sinto muito desrespeitada. (Ent. 9, NS)

Emergem do discurso problemas na relação gestão-trabalhadores de saúde, decorrentes do desgaste existenteem virtude do não atendimento às rei vindicações dos trabalhadores por meIhores condições detrabal ho, conformea seguinte afirmação:

[...] os problemas são os mesmos que a gente tinha há seis anos atrás. As limitações são as mesmas: problemas no que diz respeito às questões estruturais da unidade, limitações materiais. Isso é uma coisa crônica, são seis anos, isso é desgastante. (Ent. 9, NS)

Outro aspecto relacionado à valorização é a remuneração. Todas as participantes do estudo referiram o salário como causa de insatisfação:

Acho quea gentepoderia ganhar melhor. (Ent. $5, N S)$

Outra entrevistada complementa:

Acho que o salário no momento passa por uma precarização. (Ent. 12, NS)

Como consequências, enfatizam:

Eu não estou satisfeita mesmo é com salário. (Ent. 1, NS)

$\mathrm{N}$ ão existe uma valorização, eu sinto falta de uma valorização maior dentro da saúde mental. (Ent. 5, NS)

Q uando as entrevistadas se referem à falta de valorização na saúde mental, estão comparando com outros campos de atuação, particularmente o da medicina, em que os profissionais são mais bem remunerados.

Assim, os achados desta pesquisa, no que se refere à insati fação com os salários, são convergentes com os resultados encontrados no estudo realizado em Roma no qual foi investigada a satisfação entre profissionais de saúde mental ${ }^{15}$.

Precarização do trabalho em saúde

O processo de implantação do SUS promoveu transformações no tocante à organização dos serviços de saúde e de saúde mental. No entanto, a gestão do trabal ho ainda se constitui um dos grandes nós críticos do sistema. Considerando que ocorreu a precarização do trabalho em saúde, representada pela desregulamentação eflexibilização na forma de contratação dos trabalhadores, inclusive sem o estabelecimento de vínculo empregatício com a administração pú- blica, observa-se total desproteção social e desrespeito aos direitos trabalhistas com salários "achatados" e condições de trabal ho insatisfatórias e, em consequência, a não democratização das relações de trabal ho ${ }^{4}$.

Os discursos a seguir apontam a precarização do trabalho em saúde como um problema na gestão do trabalho em saúde mental, expressa na flexibilização das relações, a qual representa causa de insatisfação dos trabalhadores.

[...] a insegurança também da gente não ter concurso. Se hoje a gente está aqui, mas amanhã não sabe. (Ent. 1, NS)

Hoje o serviço passa por uma precarização, as diversasformas contratuais; aqui existem profissionais concursados, profissionais terceirizados. (Ent. $12, \mathrm{NS})$

É possível inferir que a flexibilização pode provocar consequências danosas ao trabalhador, gerando tensões, insegurança e medo. A pesar da necessidade de lutar por seus direitos trabal histas e por melhores condições de trabalho, entre os trabal hadores predomina o receio de perder 0 emprego em virtude da instabilidade, manifestado na expressão "querer lutar por nossos direitos e não poder" (Ent. 1, NS).

Estudos nos quais são abordadas as condições de trabalho e a satisfação de trabalhadores desaúdemental realizados no Brasil complementam a discussão ora exposta, quando se referem à diversidade de vínculos empregatícios dentro de uma mesmainstituição, com as precárias condições de trabalho, tais como salário, carga horária e ben efícios, como principais condicionantes de satisfação no trabalho $0^{5,16}$.

Além disso, o encontro cotidiano no interior dos serviços de saúde mental entre trabal hadores com diversas formas contratuais também tem gerado conflitos e disputas entre os membros da equipe. Esse fato também pode ser evidenciado no seguinte discurso:

Existe diferença entre os profissionais. Existe uma facção: são os concursados, os terceirizados, e isso gera conflitos. Eu fui a primeira terceirizada e eu não era bem aceita. [...] embora eu tenha conquistado o meu espaço ao longo do tempo. (Ent. 8, NS)

Segundo se apreende nas diversas formas de inserção no serviço público, no caso particular dos Caps elas têm corroborado para que esses serviços se configurem como arenas de disputas e conflitos entre os trabalhadores. Imprime-se, portanto, a necessidade de delimitação de território por parte dos que compartilham o mesmo ambiente de trabalho. 
Consoante essas afirmações, deve-se considerar quea política neoliberal deflexibilização da inserção do trabalhador no mundo do trabalho, intensificada na década de 1990, a qual foi adotada pelo governo federal, e seguida, em boa medida, pelos governos estaduais e municipais, produziu efeitos deletérios no SUS - pois nas instituições verifica-se um grande volume de contratações deserviços por meio da terceirização. Dessa forma, o processo de trabalho e o mundo do trabalho estão se transformando de forma significativa, alterando a modalidade de inserção e os vínculos empregatícios, a forma de remuneração e, muito fortemente, os modos de organização do trabalho, configurando-se em arenas competitivas, individualizadas. Enfim, em ambientes pouco saudáveis ${ }^{17}$.

\section{Relações estabelecidas}

no ambiente de trabalho

Com referência às relações dos trabalhadores no ambiente de trabalho, apreende-se dos discursos que podem ser causa de satisfação ou insatisfação, dependendo de como elas são estabelecidas. No tocanteà relação com os coordenadores, há convergência de 17 trabal hadoras quando referem:

[...] é boa, de amizade, quando a gente precisa de um apoio ele tá pra ajudar. (Ent. 15, NM)

Duas trabal hadoras têm opinião divergente:

É um pessoal que decide as coisas muito sozinha. A oficina terapêutica que aconteceu agora, a coordenação programou sem a minha participação (Ent. 10, NS)

Percebe-se boa receptividade dos coordenadores, no sentido de escutar e acolher as demandas dos trabalhadores. Conforme pode ser apreendido, os coordenadores têm se apresentado como catalisadores dos "problemas", demandas que escapam da governabilidade dos trabalhadores. Contudo, parece não existir essa abertura para todos os trabalhadores.

Com referência à relação dos trabalhadores entre si, eles revelam um bom relacionamento. Tal fato possibilita uma integração na equipe multiprofissional, conforme demonstrado nos discursos:

A equipena qual eu trabalho é maravilhosa. A sati sfação de trabalhar com a equi peémuito grande. (Ent. 4, NS)

É uma equipe onde a gente consegue interagir, trabalhar de forma interdisciplinar. (Ent. 4, NS)

Emerge nos discursos uma perspectiva de construção coletiva do trabalho nos Caps, sobretudo quando estão diante de demandas dos usuários cuja resolução requer ações as quais ultrapassam a esfera de atuação técnica de sua profissão. Essa postura indica a existência de cooperação mútua entre esses trabalhadores na construção de uma prática de saúde mental interdisciplinar, como determinante de satisfação dos trabalhadores.

Porém, emergiram divergências referentes às relações com a equipe de trabal ho. Desse modo, outras entrevistadas sinalizam conflitos no interior das equipes, gerando insatisfações, quando ponderam:

A equipe às vezes não comunga com os mesmos objetivos. Isso gera indisposições com colega. (Ent. 8, NS)

Os conflitos podem ser decorrentes da dificuldade decongregar todos os membros da equipe em torno de determinados objetivos, devido às discordâncias pessoais não superadas com vistas ao consenso. Provavelmente, isso pode conduzir a fragmentação das ações, ocasionando dificuldades na organização do trabalho, à medida que alguns trabalhadores podem eventualmente se recusar a operar determinadas tarefas em virtude da sua oposição ao objetivo proposto. Por conseguinte, pode ter impacto na organização do trabalho.

Quanto às relações estabel ecidas com os usuários, todas as entrevistadas as consideram como causa de satisfação, a exemplo do discurso:

Eu considero a minha relação com os usuários o único motivo para estar aqui. É o meu motivo maior de satisfação. (Ent. 6, NS)

Em estudo realizado no Reino Unido sobre estresse e satisfação entre profissionais de saúde mental, os dados divergem desse contexto analisado, pois nele a principal causa de satisfação são as relações dos membros da equipe entre si, seguidas do trabalho com os pacientes ${ }^{18}$.

Participação na organização do trabalho: a possibilidade de inovar

As entrevistadas revelam a possibilidade de empreender novos projetos como determinante de maior satisfação no trabal ho desenvolvido no Caps. O discurso de uma trabalhadora é representativo dessa afirmação:

Eu acho que a liberdade de fazer, de tá [sic] elaborando projetos de saúde mental na atenção básica, pra mim foi muito valioso, [...] dá prazer. (Ent. 6, NS)

O discurso revela a satisfação dos trabalhadores decorrente da abertura à expressão de sua capacidade deinovação elaboral, mediantea inovação e a execução de novas ações de saúde. 
Acredita-se que é preciso apostar na capacidade criativa do trabalhador, na sua expressão de subjetividade, permitindo sua manifestação. Ou seja, promover a participação do trabalhador na gestão da organização dos serviços e das práticas de saúde, tendo em vista a transformação desses trabalhadores em sujeitos, protagonistas do seu processo de trabalho, o que significa atribuir-Ihes maior coeficiente de autonomia, como estratégia de democratização da gestão e das relações de trabalho ${ }^{19}$.

\section{A distância do local de trabalho}

Em relação aos aspectos externos ao ambiente e à organização do trabalho, mas passíveis de inferir na satisfação dos trabalhadores, foi referida a distância do trabalho. Os discursos de duas entrevistadas convergiram, aqui representados:

Gosto muito daqui porque é perto da minha casa. (Ent. 19, N M)

Como é possível perceber, morar próximo do trabalho colabora positivamente para a satisfação dos trabalhadores. Ao contrário, a localização do trabal ho distante da residência, ocasionando um longo deslocamento físico do empregado, constitui causa de insatisfação, segundo retrata o discurso:

[...] a questão da distância. Então, o deslocamento gera insati fação. (Ent. 6, NS)

Consoante essa afirmação, alguns autores ${ }^{20}$ também consideram que a grande distância ocasiona insatisfação. Nesse caso, além do risco de incompreensão da chefia imediata em virtude dos possíveis atrasos decorrentes do tempo despendido na locomoção, tem-se um maior ônus relacionado ao transporte utilizado para o deslocamento.

\section{Consequências da (in)satisfação no trabalho}

Diante das situações de insatisfação experimentadas continuamente no ambiente de trabaIho, algumas entrevistadas denotam sofrimento psíquico. Aliás, a insatisfação já representa, por si só, uma expressão de sofrimento ${ }^{21}$. A representação a seguir retrata essa afirmação:

[...] a insatisfação, por outro lado, porque eu me decepcionei um pouco. Eu entrei acreditando mais no serviço. (Ent. 7, NS)

Inicialmente, o sofrimento psíquico foi evidenciado em forma de decepção, após anos de trabal ho sem ocorrer mudanças significativas no ambiente e nas relações de trabalho. Aqui, podese inferir que existem dissonâncias entre as dire- trizes de funcionamento dos serviços e sua operacionalização.

Determinadas conformações de gestão e de organização dos processos de trabalho podem ser prejudiciais à saúde dos trabalhadores e "da instituição"22. Por conseguinte, as situações de (in) satisfação no trabalho têm consequências para o trabalhador, as quais podem influenciar, inclusive, seu comportamento na instituição. Assim, identifica-se que, independentemente da concepção de satisfação no trabalho adotada, não há como refutar que ela interfere no processo de saúde-doença e, consequentemente, no ambiente de trabalho e na vida pessoal. Portanto, a (in)satisfação no trabalho pode influir na saúde física e mental, bem como no comportamento das pessoas e na qualidade de vida dos trabal hadores ${ }^{13}$.

Outra forma segundo a qual o sofrimento psíquico dos trabalhadores tem se manifestado é na tensão entre vida pessoal e a vida no trabaIho. Os trabal hadores se policiam no sentido de não permitir que sua insatisfação interfira nas relações sociais extratrabalho:

Eu tento não levar para minha vida os problemas que tenho aqui dentro. Eu sei, assim, equilibrar o daqui e o de fora. Eu não deixo misturar. (Ent. 13, NM)

O discurso torna evidentea preocupação dos trabalhadores em não "levar seus problemas de trabalho para casa e vice-versa". É como se o mundo do trabalho fosse isolado da vida pessoal e social. Para manter essa separação, é preciso um contínuo esforço por parte do trabalhador e autocontrole. Portanto, impõe uma tensão de ordem psíquica.

Considerando que o trabalho, além de assegurar a sobrevivência, se constitui em principal dispositivo para a coprodução do sujeito, tornase premente que o mundo do trabal ho éindissociável da vida particular de quem o exerce ${ }^{13}$.

0 sofrimento gerado pelo ambiente de trabaIho, sobretudo pelas condições de trabal ho e remuneração, pode se tornar intenso, permeado pela angústia, particularmente quando o trabaIhador está exposto por longo período de tempo, como é o caso da entrevistada a seguir, que está no serviço desde o início do seu funcionamento.

Eu já não tenho mais prazer como tinha antes, em trabalhar. E acabo achando que faço muito pouco, [...] fico sempre com a impressão que estou em falta eisso me deixa insatisfeita. Então dá muita angústia. (Ent. 9, NS)

A falta de prazer ea angústia referida no discurso retratam a imensa insatisfação da infor- 
mante. Portanto, ao se considerar a satisfação no trabalho como prazer, o contrário, ou seja, a insatisfação, significa sofrimento ${ }^{13}$. N esse sentido, entende-se o prazer-sofrimento como uma vivência subjetiva do próprio trabalhador, mas que pode ser compartilhada coletivamente e influenciada pelo trabalho. Pensar o sofrimento como vivência, a qual pode ser compartilhada, significa inseri-lo em dimensão política, uma vez que envolve a presença do outro no campo da existência do sujeito ${ }^{23}$.

No discurso, emergiu também um sentimento de culpa, quando afirma: "fico sempre com a impressão que estou em falta". Essa autoculpabilidade caracteriza o sofrimento psíquico que, além desta, apresenta outras características como sensação deincompetência, redução da autoestima, piora do rendimento e qualidade profissional com perda da atenção, má acolhida dos usuários e equipe de trabalho, com tendências a posturas culpabilizantes, tanto no trabalho como nas demais relações sociais ${ }^{24}$.

Por conseguinte, o sofrimento psíquico é capaz de desestabilizar a identidade pessoal e profissional, conduzindo a problemas mentais. Ao mesmo tempo, porém, configura-se como elemento para a normalidade, quando existe um compromisso entre o sofrimento e a luta individual e coletiva contra ele - sendo o saudável não uma adaptação, mas 0 enfrentamento das imposições e pressões do e no trabalho, geradoras da desestabilidade psicológica ${ }^{23}$. Assim, quando o sofrimento é superado, toma seu lugar o prazer.

Entre as implicações da insatisfação na saúde dos trabalhadores, foi também identificada alteração na saúde física:

Tem horas que fico assim, [...] e eu me sinto sufocada. Tem dias que eu saio daqui estressada, com muita dor de cabeça. (Ent. 18, NM )

0 adoecimento pode se manifestar em forma de estresse e dor física. Os processos de adoecimento resultam do profundo desgaste provocado também pela atividade laboral, quando o trabalhador éexposto continuamentea situações estressoras no seu ambiente de trabalho.

É pertinente considerar que as doenças de correntes de sofrimento físico epsíquico são importantes causas de licenças médicas, afastamentos, enfim, deabsenteísmo nas instituiçõe ${ }^{13}$. Dito isto, torna-se evidente a necessidade de adoção de estratégias de enfrentamento dessa questão, visando à sua prevenção e/ou inversão de tais "complicações".

Não obstante, se o serviço de saúde, em meio às transformações ocorridas nos últimos anos, conseguir atender, de alguma forma, às necessidades de realização pessoal eprofissional dos trabalhadores, promovendo sua satisfação, os resultados tendem a ser positivos, na vida do trabalhador e da instituição, os quais poderão se expressar pelo maior rendimento por parte dos trabal hadores e consequente melhoria na qualidade dos serviços. 0 discurso seguinte, entre outros, revela que quanto maior a satisfação do trabal hador, melhor será seu desempenho na instituição:

[...] leva ao comprometimento de todo mundo em fazer o paciente estar bem, sentir melhor. (Ent. $14, \mathrm{NM}$ )

0 trabal hador insatisfeito poderá apresentar descompromisso e, consequentemente, um baixo rendimento no trabalho, contribuindo para menor qualidade na assistência por ele prestada.

D essemodo, revela-sequea satisfação no trabalho poderá interferir positivamente, ou não, na qualidade dos serviços de saúde, na medida em que maior ou menor nível de satisfação poderá implicar o rendimento e o compromisso do trabalhador.

\section{Consideraçõesfinais}

0 trabalho em saúde mental apresenta-se permeado de especificidades, as quais requerem dos trabalhadores habilidades para lidar com o ser humano, tendo em vista compreendêlo numa perspectiva da integralidade do cuidado em saúde. Sobretudo porque se lida no cotidiano com o sofrimento e a loucura, o que torna o ambiente permeado por intensa produção subjetiva e intersubjetiva.

Além disso, há que se consi derar as transformações ocorridas no mundo do trabalho e os movimentos de reforma do setor saúde, os quais se configuram como processos promotores de mudanças na gestão e na organização dos processos de trabalho em saúde, e em saúde mental.

Assim, os trabalhadores estão expostos a diversas situações, as quais podem ocasionar maior ou menor (in)satisfação. A satisfação é determinada por aspectos intrínsecos e extrínsecos ao ambientedetrabal ho etem consequências na vida do trabalhador, nas suas mais diferentes áreas.

0 estudo permitiu evidenciar, entre os determinantes de (in)satisfação dos trabalhadores, aspectos tanto intrínsecos quanto extrínsecos ao ambiente e à organização do trabal ho.

Asprincipais causas de insatisfação queemergiram são intrínsecas ao trabalho, entre elas: as- 
pectos inerentes à estrutura física e material; relações conflituosas dentro da equipe e com os gestores/coordenadores de serviços relacionados à organização do trabalho; o salário e a flexibilização da inserção no serviço público, ambos relacionados à gestão do trabalho.

$\mathrm{Na}$ satisfação dos trabalhadores, emergiram determinantes considerados como internos ao ambiente de trabal ho, entre eles: as relações estabelecidas com os usuários, referida por todas as entrevistadas como motivo de satisfação; a possibilidade de participar de novos projetos; o reconhecimento profissional; e as relações com a equipe. Somente um determinante externo ao ambiente de trabalho emergiu como causa de satisfação: a distância do trabalho.

No entanto, pode-seinferir que alguns aspectos psicossociais do trabalho são responsáveis tanto pela satisfação como pela insatisfação, isto é: a mesma categoria de eventos determina tanto uma quanto a outra, a depender de como eles se apresentam e são avaliados pelo trabal hador.

Ao considerar que a (in) satisfação tem consequências na vida do trabalhador, foi possível perceber sua interferência na saúde física emental dos participantes, bem como seu potencial de repercussão no comportamento organizacional esocial do trabalhador, por conseguinte, inferindo na qualidade dos serviços de saúde.

Osachados evidenciam a persistência da precarização do trabalho no SUS, particularmente em serviços desaúdemental, fornecendo elementos importantes para uma reflexão acerca da gestão dos serviços e do trabal ho. Tornam evidente a necessidade de adoção de medi das por parte da administração pública, no sentido de tornar possível uma política de gestão do trabalho, para superação da precarização das relações de trabaIho. Além disso, é preciso melhorar as condições de trabalho, incluindo a aquisição de materiais necessários para o desenvolvimento das atividades. Ressalta-se também a necessidade de democratização das relações de trabalho, mediante transformações na organização dos processos de trabalho, com a finalidade de promover autonomia para os trabalhadores, possibilitando-Ihes oportunidade de criação, implantação e imple- mentação de novos projetos. Em síntese, edificar a abertura de espaços para a construção coletiva do trabalho e participação na gestão.

Finalmente, enfatiza-se que, apesar de todos os serviços de saúde mental estudados encontrarem-se localizados no mesmo município, eles apresentam diferenças/peculiaridades que vão desde a estrutura física à forma de organização do processo de trabalho, passando pela composição das equipes, gerando resultados, muitas vezes, particulares e singulares de cada instituição. N esse sentido, acredita-se que os resultados aqui apresentados não podem ser generalizados.

\section{Colaboradores}

JMX Guimarães participou da concepção teórico-metodológica, da coleta e análise dos dados e redação do artigo; M SB Jorge e M M A Assis, da concepção teórico-metodológica e da revisão do texto.

\section{Agradecimentos}

Aos trabalhadores de saúde mental dos Caps de Fortaleza, que prontamenteaceitaram participar da pesquisa; à Fundação Cearense de Apoio ao Desenvolvimento Científico e Tecnológico, pelo apoio financeiro para o desenvolvimento da pesquisa. 
1. Reis MAS, Fortuna CM, Oliveira CT, Durante MC. A organização do processo de trabalho em uma unidade de saúde da família: desafios para a mudança das práticas. Interface - Comunic, Saúde, Educ 2007; 11:655-666.

2. Amarante P. Loucura, cultura e subjetividade: conceitos e estratégias, percursos e atores da reforma psiquiátrica brasileira. In: Fleury $\mathrm{S}$, organizadora. Saúde e Democracia: a luta do Cebes. São Paulo: Lemos Editorial; 1997. p. 163-185.

3. Campos GWS. Considerações sobre a arte e a ciência da mudança: revolução das coisas e das pessoas - o caso da saúde. In: Cecilio LCO, organizador. Inventando a mudança na saúde. 3a ed. São Paulo: Hucitec; 2006. p. 29-87.

4. Jorge MSB, Guimarães JMX, Nogueira MEF, M oreira TMM, Morais APP. Gestão de recursos humanos nos Centros de Atenção Psicossocial no contexto da Política de Desprecarização do Trabalho no Sistema Ú nico de Saúde. Texto Contexto Enferm 2007; 16:417-425.

5. Schraiber LB, Machado MH. Trabalhadores da saúde: uma nova agenda de estudos sobre recursos humanos em saúde no Brasil. In: Fleury S. Saúde e democracia: a luta do Cebes. São Paulo: Lemos Editorial; 1997. p. 281-297.

6. Pitta AM F, Silva Filho JF, Souza GW, Lancman S, Kinoshita RT, Cavalcanti MT, , Valentini WH. Determinantes da qualidade de serviços de saúde mental em municípios brasileiros: estudo da satisfação com os resultados das atividades desenvolvidas por pacientes, familiares e trabalhadores dos serviços. J Bras Psi 1995; 44(9):441-452.

7. Ishara S, Bandeira M, Zuardi AW. Public psychiatic services: job satisfaction evaluation. Rev Bras Psiquiatr 2008; 30(1):38-41.

8. Rebouças D, Abelha L, Legay LF, Lovisi GM. Satisfação com o trabalho em saúde mental: um estudo de satisfação e impacto. Cad Saude Publica 2008; 24(3):624-632.

9. Uchimura Y, Bosi MLM. A polissemia da qualidade na avaliação de programas e serviços de saúde: resgatando a subjetividade. In: Bosi MLM, M ercado FJ, organizadores. Pesquisa qualitativa de serviços de saúde. Petrópolis: Vozes; 2004. p. 75-98.

10. Martinez MC. As relações entre satisfação com aspectos psicossociais no trabalho e a saúde do trabalhador [dissertação]. São Paulo: Universidade de São PauIo; 2002.

11. International Labour Office (ILO). Phychosocial factors at work: recongnition and control. Report of the joint ILO/WHO Comitte on Occupational Health - Ninth Session. Geneva: International Labour Office; 1984.

12. Minayo MCS. 0 desafio do conhecimento: pesquisa qualitativa em saúde. 9a ed. revista e aprimorada. São Paulo: Hucitec; 2006.
13. Fontanella BJB, Ricas J, Turato ER. Amostragem por saturação em pesquisas qualitativas em saúde: contribuições teóricas. Cad Saude Publica 2008; 24:12-27.

14. Campos GWS. Reforma política e sanitária: a sustentabilidade do SUS em questão? Cien Saude Colet 2007; 12(2):301-306.

15. Gigantesco A, Picardi A, Chiaia E, Balbi A, Morosini $P$. Job satisfaction among mental health professionals in Rome, Italy. Community Mental Health Journal 2003; 39:349-355.

16. Rebouças D, Legay LF, Abelha L. Satisfação com 0 trabalho e impacto causado nos profissionais de serviços de saúde mental. Rev Saude Publica 2007; 41:244-250.

17. Machado MH. Trabalhadores da saúde e sua trajetória na reforma sanitária. In: Lima NT, Gerschman S, Edler FC, Suaréz JM, organizadores. Saúde e democracia: história e perspectivas do SUS. Rio de Janeiro: Editora Fiocruz; 2005. p. 257-284.

18. Reid Y, Johnson S, M orant N, Kuipers E, Szmukler G, Thornicroft G, Bebbington P, Prosser D. Explanations for stress and satisfaction in mental health professionals: a qualitative study. Soc Psychiatry Psychiatr Epidemiol 1999; 34:301-308.

19. Campos GWS. U m método para a análise e co-gestão de coletivos. 3a ed. São Paulo: Hucitec; 2007.

20. Del Cura M LA, Rodrigues ARF. Satisfação do profissional enfermeiro. Rev Lat Am Enfermagem 1999; 7:21-28.

21. M artinez MC, Paraguay AIBB. Satisfação e saúde no trabalho: aspectos conceituais e metodológicos. Cad de Psicologia Social do Trabalho 2003; 6:59-78.

22. Sato L. Replanejamento do trabalho como processo de construção e de negociação de significados. In: Borges LH, Moulin M GB, Araújo MD, organizadores. Organização do trabalho e saúde: múltiplas relações. Vitória: Edufes; 2001.

23. Ferreira MC, Mendes AM. "Só de pensar em vir trabalhar, já fico de ma humor": atividade de atendimento ao público e prazer-sofrimento no trabaIho. Estud Psicol (Natal) 2001; 6(1):93-104.

24. Rollo AA. É possível valorizar o trabalho em saúde num mundo "globalizado"? In: Santos-Filho SB, Barros MEB. Trabalhador da saúde: muito prazer! Protagonismo dos trabalhadores na gestão do trabaIho em saúde. Ijuí: Ed. Unijuí; 2007.

Artigo apresentado em 04/09/2008

Aprovado em 04/12/2008

Versão final apresentada em 10/01/2009 